\title{
A Case of Dextrocardia with Single Atrium with A-V canal Defect with Pulm Hypertension- Case Report with Review
}

\author{
MD. FARUQUE ${ }^{1}$, MD. ABDUR RASHID ${ }^{2}$, M.A MUTTALIB ${ }^{1}$, SYED AMINUL ISLAM ${ }^{1}$, MD. HAFIZUR RAHMAN ${ }^{1}$ \\ ${ }^{1}$ Department of Cardiology, NICVD, Dhaka, ${ }^{2}$ Department of Anatomy, BMC, Dhaka. \\ Address for Correspondence: Dr. Md. Faruque, Professor of Cardiology, NICVD, Dhaka
}

\begin{abstract}
:
Congenital Heart disease is although uncommon but is not rare.

Complex congenital Heart disease is more rare. The survivality is less. Most of the patient die in the Early childhood. Our patient survive up to the age of 23 yrs. Early diagnosis \& early corrective surgery will prolong the survivality \& even normal life.
\end{abstract}

\section{Case Report:}

Can we sustain the peaceful smile of the young lady? She is Miss Rabeya, 23 years old, a student of Honors in Accounting. She has been still hatching a great dream that someday she will be able to complete her graduation and to get rid of her breathing difficulty. But is it ever possible for her? She got admitted in NICVD few months back with shortness of breath on exertion more for 06 months, cough and haemoptysis for 02 days, Blue discoloration of lips and nail since childhood. Her

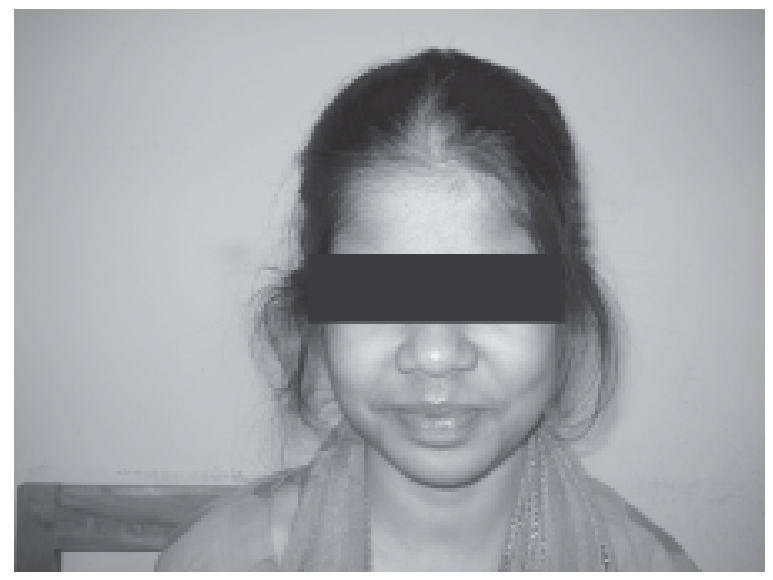

mother has stated that she was born through normal vaginal delivery and her pregnancy was uncomplicated. She has another 5 issues and all of them enjoying the best of their health. Rabeya has been immunized as per EPI schedule. When she was at five her breathing difficulty has been started along with the appearance of blue discoloration of lips and nails. She was seen by local physician and referred her to Dhaka for proper evaluation. An Echocardiography was done at that time and the attending physician advised to put her on medication rather than any surgical measure. She was doing better for 10 years. After she developed shortness of breath of CCS class-I to II and still she was put some medications by local physicians. For last 06 month her illness drastically increased which compelled her to come NICVD. She started menstruation at the age of 13 and she has regular cycles. She came from a middle class family and resides in tin shed house and took arsenic free tube-well water and use sanitary latrines. She took Tablet Frusemide, Spironolactone, Theophyline and antibiotics frequently.

She was depressed, lean and thin, orthopnoeic and has male pattern distribution of hairs in face. She was mildly anaemic, cyanosed and had clubbing of both fingers and toes' nails, dependent oedema and yellowish discoloration of peripheries. JVP was greatly raised with prominent ' $\mathrm{V}$ ' wave. Pulse rate was $80 / \mathrm{min}$, regular but low volume and BP was 100/80 mm.Hg. Liver was enlarged of about $6 \mathrm{~cm}$ in mid clavicular line which was mildly tender. Chest was grossly deformed as pigeon shaped with the apical impulse at right $6^{\text {th }}$ intercostals space, $10 \mathrm{~cm}$ away from mid sternal line and normal in character.Trere were right parasternal heave and palpable P2. A pansystolic murmur was heard at the lower right parasternal area which was increased in intensity when the breath held at inspiration.

She underwent investigations including laboratory test, ECG, Chest X-Ray echocardiography, and cardiac catheterization. All laboratory investigations revealed no abnormalities except hemoglobin percentages which was $16 \mathrm{gram} / \mathrm{dl}$ of blood. 

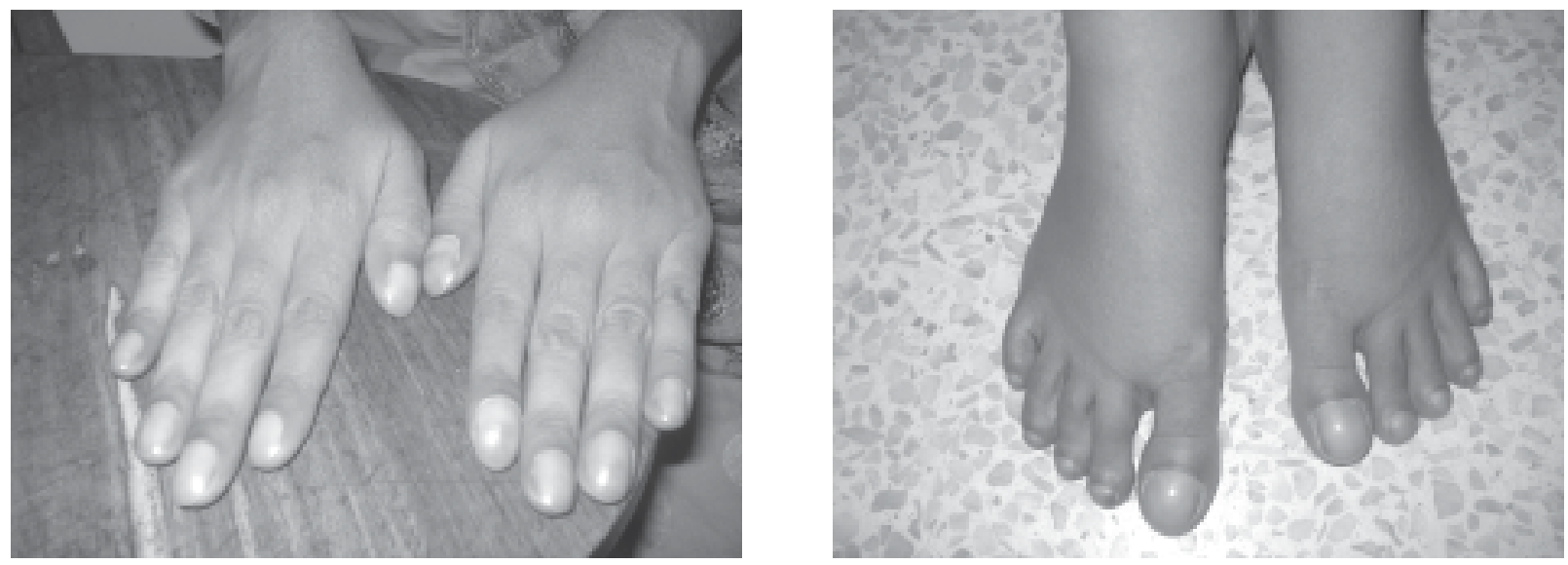

Cyanosis \& clubbing of the nails.

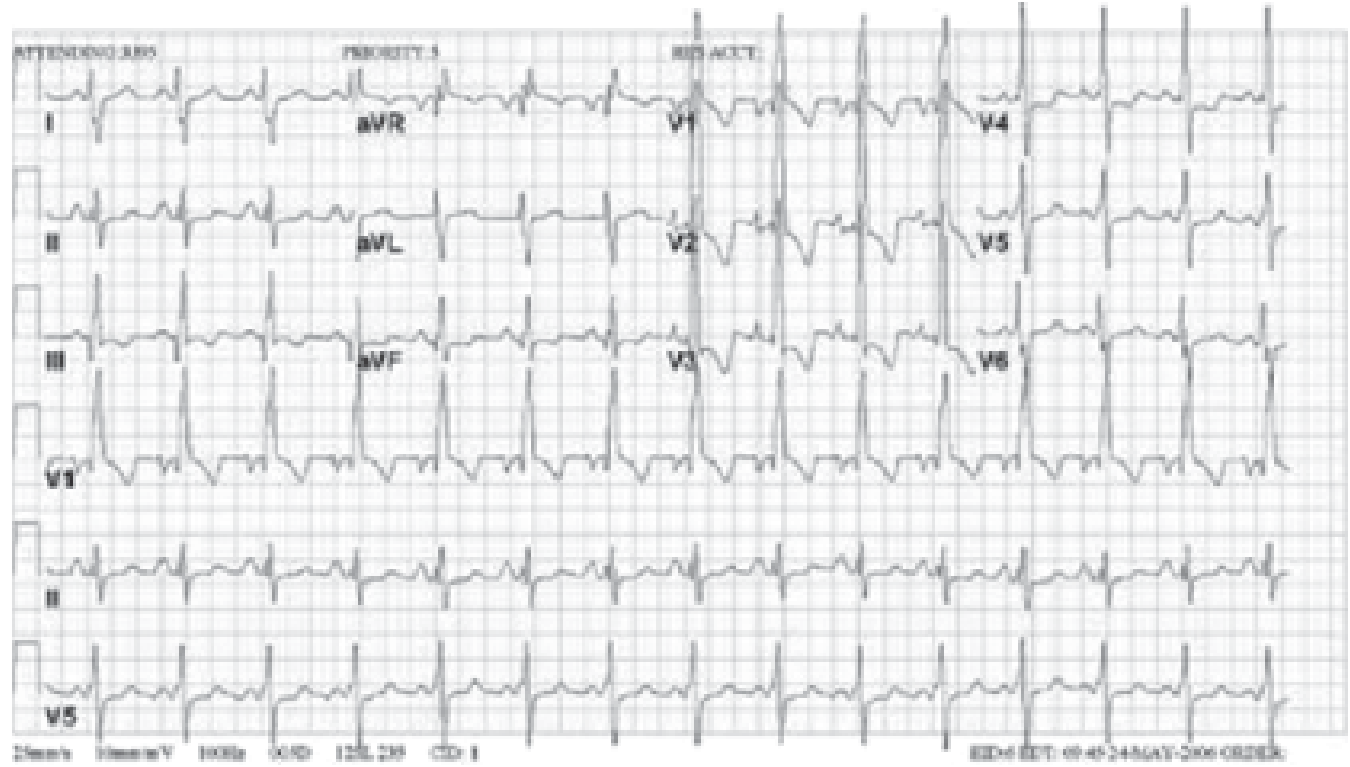

ECG showed RVH with P-pulmonale.

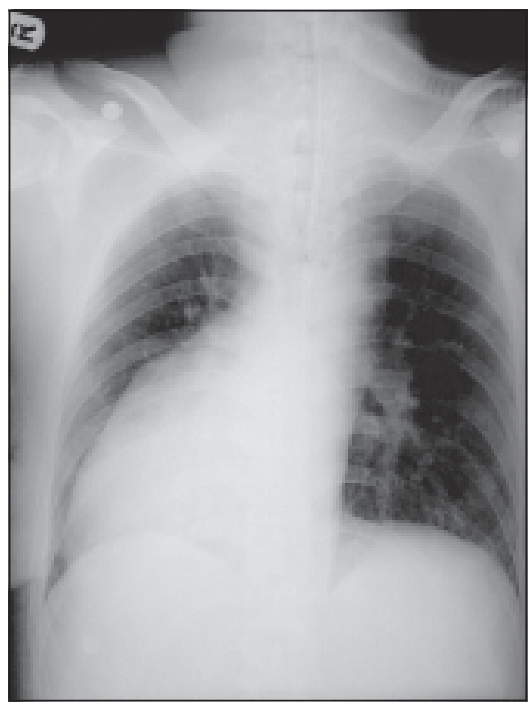

CXR showed detrocardia with Increased CTR. 
Echocardiography revealed
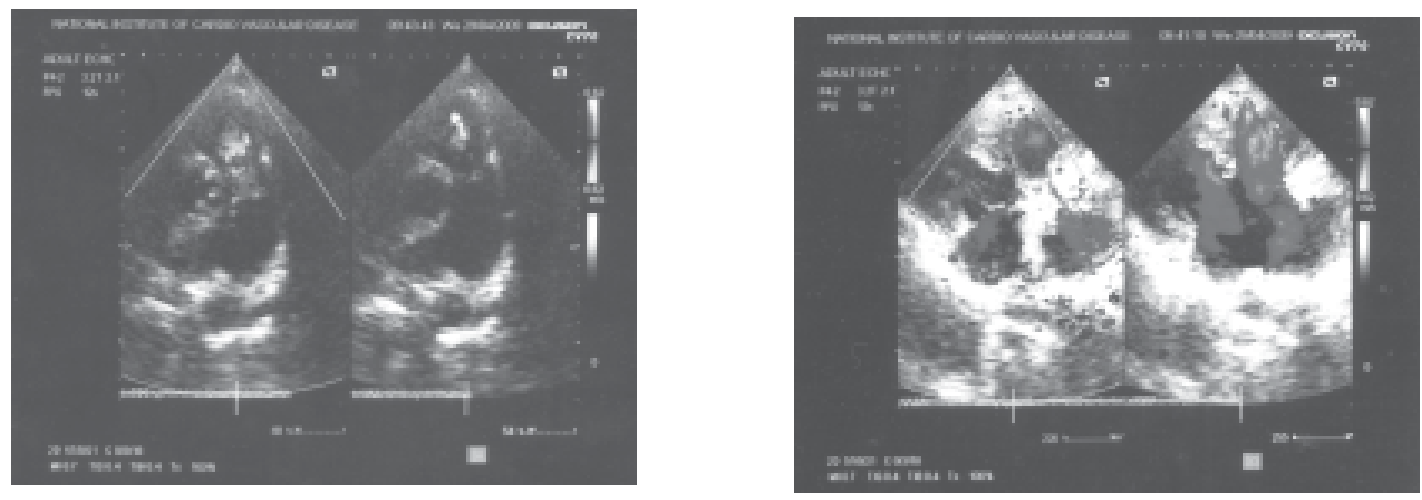

Both the pulmonary arteries are normal.

Dextrocardia present.

Regurgitation seen acroos the tricuspid and pulmonary valves.
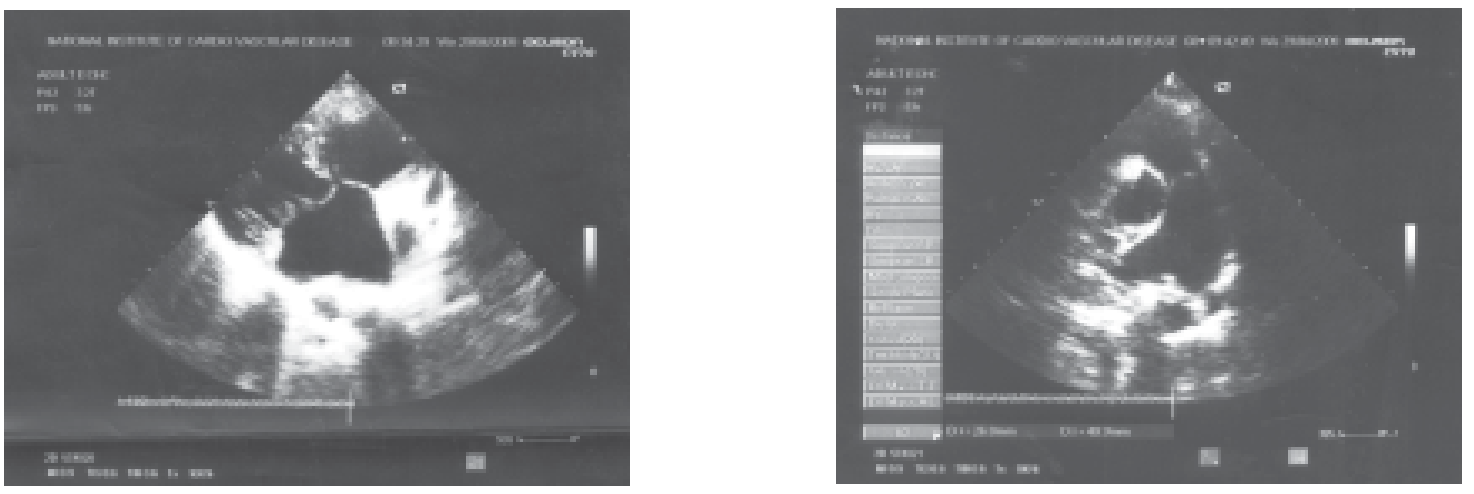

There is common atrium but separate atrioventricular vavles.
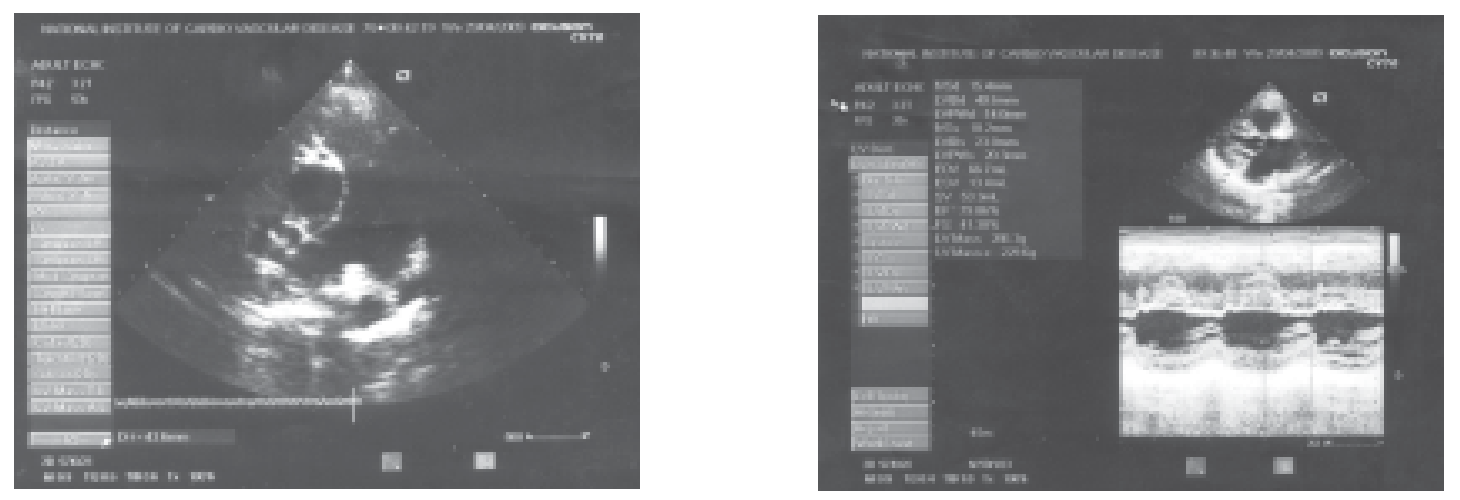

Pulmonary artery is hugely dilated. 


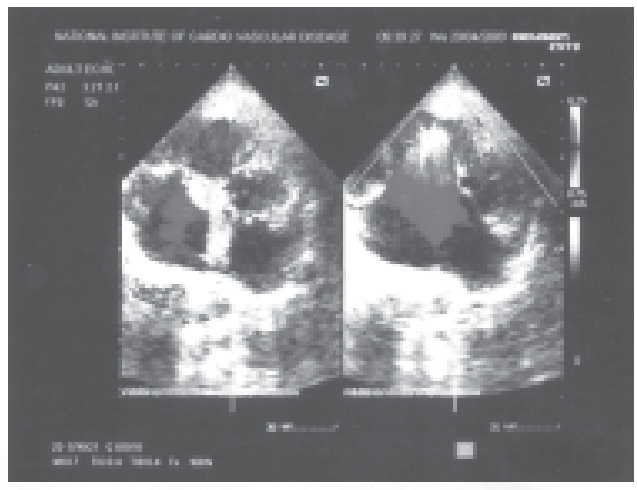

\section{NATIONAL INSTITUTE OF CARDIOVASCULAR DISEASES Sher-e-Bangla Nagar, Dhaka-1207}

ECHOCARDIOGRAPHY REPORT

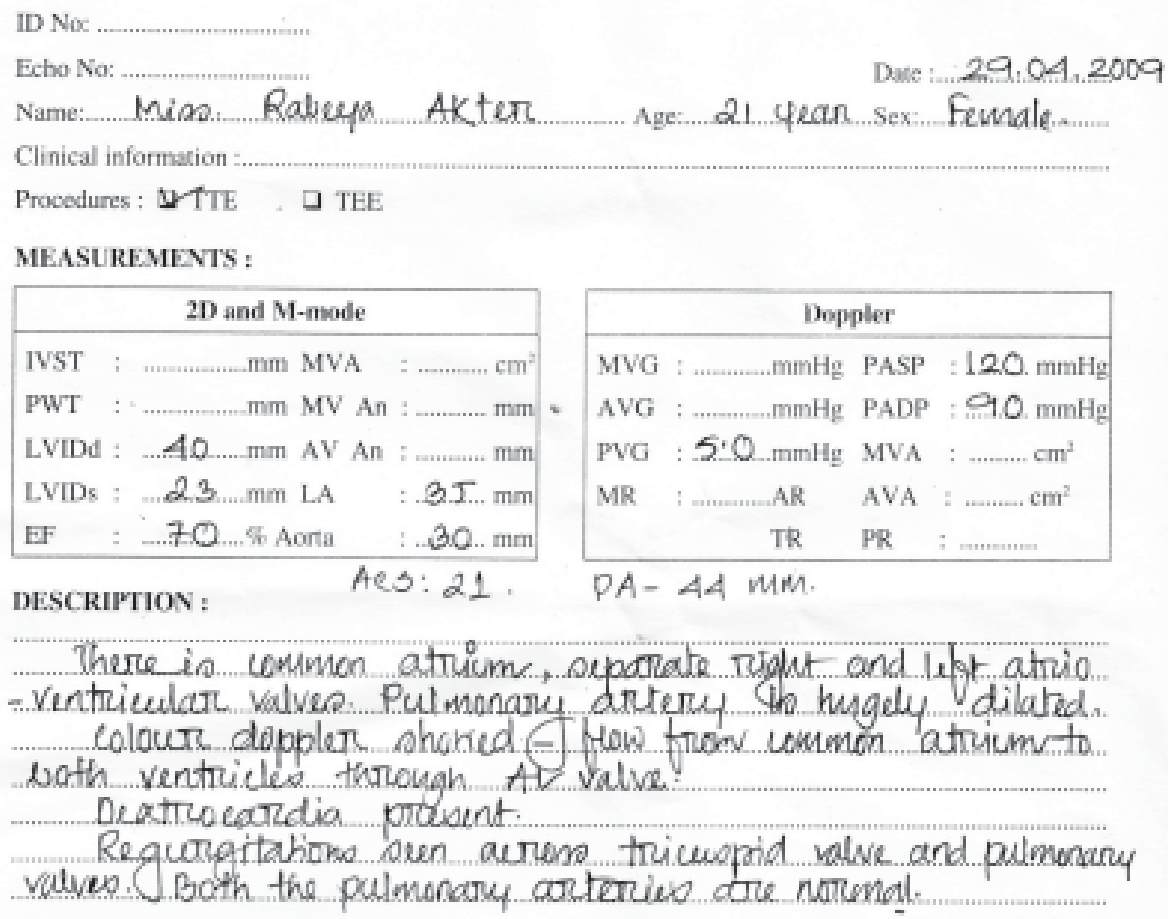

Coour Doppler showed- colour flor from common trium to either ventricle through atrioventricular vaves. 


\section{Cardiac catherization revealed:}

Dextrocardia

Single atrium

AV canal defect

Pulmonary Hypertension (12.72 wood unit) With negative reversibility test.

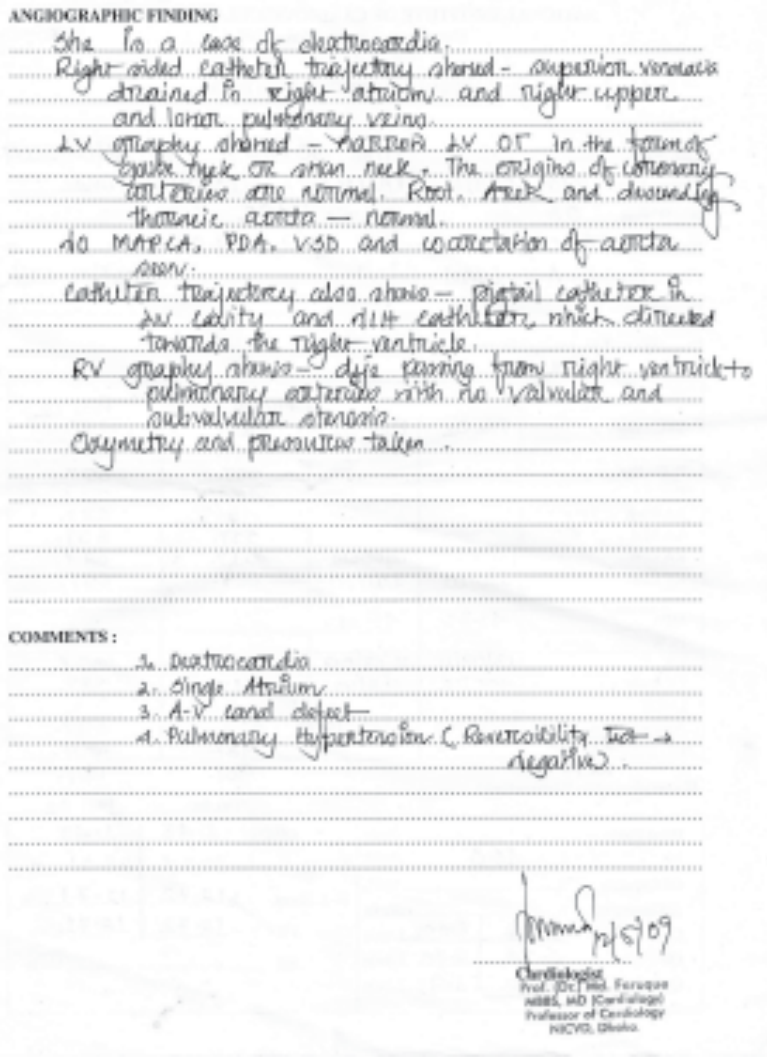

\section{Introduction:}

AV canal defects are characterized by defects in isolation or combination including an ASD in the lowermost part of the atrial septum (Ostium primum), a cleft of the mitral valve or VSD. In complete AV canal defect there is a large ostium primum ASD, a large VSD in the upper muscular septum and a common AV valve straddling the ventricular septum. It results from incomplete growth of AV endocardial cushions and the AV septum. ${ }^{1}$ Rogers and Edwards described the AV canal defects into two types, complete and partial. ${ }^{2}$ Complete AV canal defect is characterized by failure of partitioning of the primitive canal into separate AV orifices. The orifice between the atria and the ventricle is guarded by a common valve with anterior valves of the anterior mitral \& septal tricuspid leaflets. Posterior leaflet arises from dorsal endocardial cushion. In most cares there is free communication between the ventricles. Rastelli and associates ${ }^{3}$

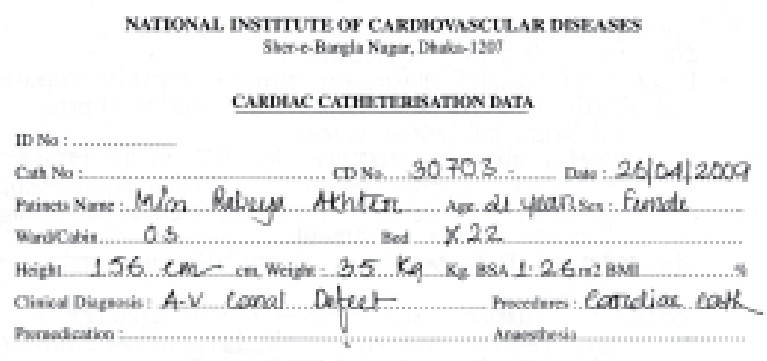

Preware and Oxymetry Data :

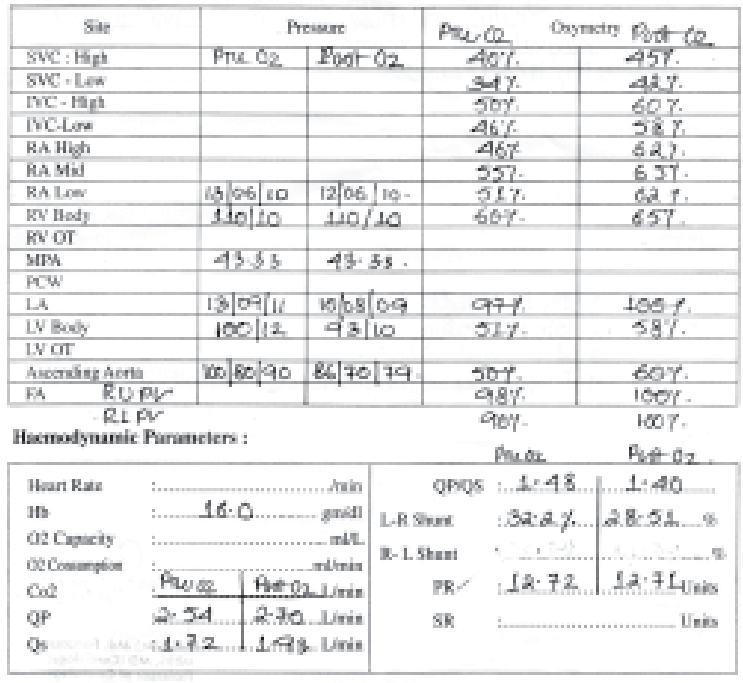

subdivided the complete type into three subgroups-types A, B \& C on the basis of the structures of the common anterior leaflet and its Chordal attachment to the ventricular septum.

\section{Discussion:}

Approximately 3 percent of infants and children with congenital heart disease have AV canal defect. About 60 to 70 percent have the complete form. More than 50 percent with complete form have associated Down syndrome. Complete form of AV canal or partial form with significant mitral regurgitation present with poor weight gain, easy fatigue, tachypnea, repeated respiratory tract infections and congestive heart failure. Physical findings in complete form of AV canal defect are those of very large VSD with full blown congestive heart failure, findings with a partial defect are those of an ASD. ${ }^{4}$ 
Growth retardation is common. Infants with complete AV canal defect quickly develops congestive heart failure. Infective endocarditis is common because of mitral valve deformity.

For Common Atrium repair is accomplished by sewing an appropriately larger pericardial patch to the atrial wall on the left atrial side of Inferior vena caval opening, to the right side of right pulmonary veins opening and beneath the superior vena cava (where there is usually a small septal remnant). For Interventricular opening the communication is closed by taking the anterior portion of pericardial patch just to the right side of the septal crest. Because of the presence of Bundle of His care must be taken to keep the suture line well away from the crest of the septum. ${ }^{5}$

Conclusion: We are trying relentlessly to find curable treatment for her in order to make her dream a reality.. But operation was not possible in severe pulmonary hypertensive state without any reversibility. In conclusion, this patient presented very early but she was unlucky to get the curable treatment and probably we can called it as the destiny which cannot be changed.

\section{Reference:}

1. Gary D. webb, Jessrey F, Smallhorn, Judith. Therrien and Andrew N. Redington. Congenital heart disease. Braunwald‘s Heart Disease. A Textbook of cardiovascular Medicine. (Eighth edition) (chapt61); 1581-83.

2. Rogers HM, Edwards JE. Incomplete division of Atrio ventricular canal with patent interatrial foramen primum. Report of five cases and review of the literature. Am Heart J 1948; 36 ; 28.

3. Omenish A, Hijazi ZM. Transcatheter closure of atrial septal defects in children \& adults using the Amplatzer septal occluder. J Intervent Cardiol 2001;14:37

4. David R. Fulton, Michael D. Freed. The Pathology, Pathophysiology, Recognition \& Treatment of congenital heart disease. Hurst : The Heart Volume-2, (11 $1^{\text {th }}$ edition); Chapter 73. P 1801-04.

5. Kouchoukos, NT.; Blackstone, EH.; Doly, DB.; Hanley, FL.; Karp, RB., Atrio ventricular septal defect, Cardiac Surgery: Kirklin, BarrattBayes, Vol-1, pp 829-31, 3rd Ed., Churchill Living stone. 